ORIGINAL ARTICLE

\title{
Survey of attitudes of senior emergency physicians towards the introduction of emergency department ultrasound
}

\author{
R E McLaughlin, A Lee, S Clenaghan, S McGovern, C Martyn, J Bowra
}

Emerg Med J 2005;22:553-555. doi: 10.1136/emj.2004.018713

See end of article for authors' affiliations

.....................

Correspondence to: Dr R E McLaughlin, Ulster Hospital, Belfast, UK; remclaughlin@tinyworld. co.uk

Accepted for publication 31 July 2004
Introduction: Emergency department ultrasound (EDU) is widely practised in the USA, Australia, parts of Europe, and Asia. EDU has been used in the UK since the late 1990s but as yet, few areas have established a practice.

Objectives: To assess the current climate of opinion with respect to the practice, constraints, and establishment of EDU among emergency department (ED) consultants on the island of Ireland.

Methods: A postal questionnaire was formulated, piloted, and assessed for ambiguity by a sample of ED consultants and an independent non-ED consultant, prior to being mailed to all ED consultants in Ireland. Results: Of the 58 consultants canvassed $46(79 \%)$ responded. Of the respondents, $40(87 \%)$ strongly agreed/agreed that EDU is appropriate and should be performed in the ED. Of these, $3(7 \%)$ are currently performing EDU; 37 (80\%) have not had formal training in EDU, however 42 (91\%) support the establishment of national guidelines for training in focused ultrasound in the ED. Problems instituting EDU were often multifactorial. Commonly highlighted difficulties included financial issues (24 respondents, $52 \%$ ) and radiology department support (16 respondents, 34\%). Other cited problems include varying interdepartmental practices (15 respondents, 33\%) and (for some EDs) low numbers of patients requiring EDU, with projected difficulties in skills maintenance.

Conclusion: Despite the vast majority of ED consultants being in favour of EDU, very few actually perform it on a regular basis or have had any formal training. Highlighted difficulties in EDU implementation included financial constraints, lack of support from radiology departments, and lack of formal training.
U ltrasound has been used for diagnostic purposes for well over 50 years. However, only in the past 15 years has it been exploited widely by non-radiologist medical practitioners. ${ }^{12}$

Emergency department ultrasound (EDU) is widely practised in the USA, Australia, parts of Europe, and Asia. In the UK and Ireland, EDU has recently attracted considerable interest, but as yet, few areas have established a practice. In response to this, a survey was carried out to assess the current climate of opinions and attitudes towards the practice of bedside EDU among ED consultants on the island of Ireland.

\section{METHODS}

A MedLine cross referenced literature search was performed to ensure this work had not been previously carried out anywhere in the UK or Ireland. A Likert style postal questionnaire was formulated and mailed to the 58 consultants in emergency medicine in both Northern Ireland (NI), which comes under the UK health service and the Republic of Ireland, which has its own health service. The three ED consultants involved in the design of this study were excluded. The questions were a mixture of six Likert style and open ended questions (fig 1) on the availability of EDU, whether it should be performed by emergency physicians, its uses, perceived obstacles faced in implementation, and training in its use. Prior to dispatch, the questionnaire was piloted and assessed for ambiguity by a sample of emergency physicians and an independent nonemergency department (ED) consultant.

\section{RESULTS}

The response rate was $79 \%(46 / 58)$. Of the ED consultants who responded, $87 \%$ (40/46) strongly agreed/agreed that EDU is appropriate and should be performed (fig 1). Despite this, only 7\% (3/46) are performing EDU in their departments. Although $80 \%(37 / 46)$ had not had any formal training, $91 \%$ (42/46) supported the establishment of National Guidelines for training in EDU (fig 2).

Perceived problems instituting EDU were multifactorial, with 52\% (24/46) citing financial issues. In addition, 34\% (16/ 46) cited lack of radiology department support as a contributory factor, 9\% (4/46) expressed their concerns with regard to skill maintenance in a small patient population, while 33\% (15/46) nominated current ED practice (that is, the. ED is inadequately staffed to provide a satisfactory service (fig 3).

One respondent commented that "National guidelines for training should be established by ED specialists and should encompass as broad a scope as the specialty determines." Conversely, some respondents expressed concerns with abuse of EDU while one felt that EDU would have no influence on patient care. Three consultants felt that EDU was unnecessary as their EDs enjoyed radiology coverage 24 hours a day, 7 days a week.

\section{DISCUSSION}

Like the stethoscope, EDU enjoys the characteristics of a genuinely useful emergency diagnostic tool. Not only is it safe, rapid, and portable, it is also non-invasive and painless. It can be performed on a haemodynamically unstable patient in the resuscitation area. However, its implementation may have been delayed by factors such as perceived "turf" issues. ${ }^{3}$

This paper documents the views of the majority of ED Consultants in the whole of Ireland. Clearly, there is a gap between the ideal and the reality: most favour its implementation, but only a few are actively engaged in EDU.

Abbreviations: ED, emergency department; EDU, emergency department ultrasound 


\section{ED ultrasound questionnaire}

1. In your view, should ultrasound be performed by Emergency Physicians?

Strongly agree
Comments: $\quad$ Agree $\square \quad$ Neutral $\square \quad$ Disagree $\square \quad$ Strongly disagree $\square$

2. Is ultrasound being performed by Emergency Physicians in your department?

$$
\text { Yes } \square \quad \text { No } \square \text { (go to 4) }
$$

3. What do you use ultrasound for? Please type or print.

4. In my hospital, significant obstacles to introducing focused ED US include: (please tick boxes that apply)
a. Patient population
b. ED practice
c. Radiology department
d. Financial
e. Other/comments.:

5. Should there be established national guidelines for training in focused ultrasound in the ED? Strongly agree $\square \quad$ Agree $\square \quad$ Neutral $\square \quad$ Disagree $\square \quad$ Strongly disagree $\square$

6. I have received formal training in focused bedside ultrasound.

$$
\text { Yes } \square \quad \text { No } \square
$$

Please add any extra comments:

Figure 1 ED ultrasound questionnaire.

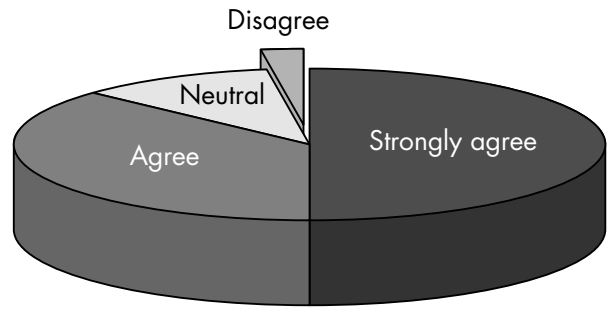

Figure 2 Should ultrasound be performed by emergency physicians?

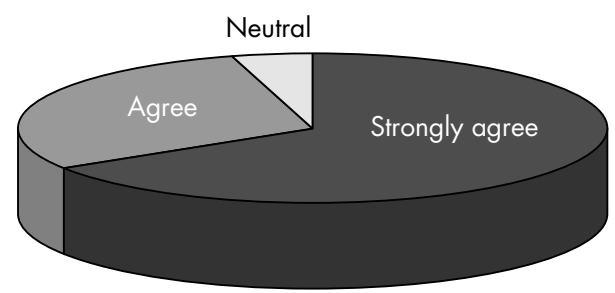

Figure 3 Support for the establishment of national guidelines for EDU training.
Several common themes have been identified as significant obstacles to progress. For example, finance is perceived as the single greatest issue preventing its implementation. However, a perfectly adequate machine can be purchased for approximately $£ 25000$.

Lack of radiology department support has been perceived as a contributory factor, but three points must be made regarding this. Firstly, having established an EDU service over the past year, we have enjoyed the full support of the radiology team. There is in fact is a body of opinion within radiology that supports the use of goal directed US by EP; ${ }^{4}$ however, we appreciate this may not be the case in every unit. Secondly, radiologists may well have reservations about nonradiologists performing and accurately interpreting US; however, recent research has shown that EDU is accurate,

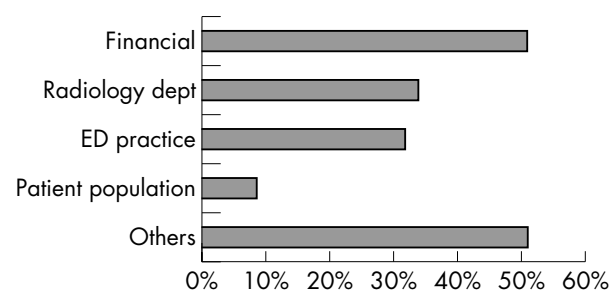

Figure 4 Perceived obstacles in the establishment of EDU. 
effective, and comparable to the radiologist gold standard. ${ }^{5-9}$ Thirdly, the concerns raised regarding radiology support may have introduced a bias. Merely asking the question may have alerted respondents to a previously unconsidered area of concern. This is a weakness of using a closed question. However, informal discussion with colleagues in other departments does draw out radiological support as a key issue.

Certainly, it is worth considering the argument that it may be difficult to maintain EDU skill levels in EDs with small catchment populations. However, Brenchley et al suggest that there is minimal skill fade with focused ultrasound by nonradiologists. $^{2}$

In our own department's experience, many of the perceived difficulties did not pose great problems and EDU was implemented fairly painlessly. However, we agree that different constraints apply to different EDs and that national guidelines in EDU are essential. At the time of writing, the Royal College of Radiology (RCR), British Medical Ultrasound Society (BMUS) and Faculty of Accident and Emergency Medicine (FAEM) are currently developing such guidelines.

\section{CONCLUSION}

Despite the fact that a large majority of ED consultants in Ireland is in favour of EDU, very few actually perform it on a regular basis or have had any formal training in its use. Perceived difficulties in its implementation include financial constraints, radiology department cooperation, and lack of formal training.

\section{Authors' affiliations}

R E McLaughlin, A Lee, S Clenaghan, S McGovern, C Martyn, Emergency Department, Ulster Hospital, Belfast, UK;

russell.mclaughlin@ucht.n-i.nhs.uk

J Bowra, Emergency Department, Liverpool Hospital, Sydney, Australia

Competing interests: none declared

\section{REFERENCES}

1 Heller M, Jehle D. Ultrasound in emergency: out of the acoustic shadow. Ann Emerg Med 1997;29:380-2.

2 Brenchley J, Sloan JP, Thompson PK. Echoes of things to come; ultrasound in UK emergency medical practice. J Accid Emerg Med 2000;17:170-5.

3 Plummer D. Whose turf is it anyway? Diagnostic ultrasonography. Acad Emerg Med 2000;7:186-7.

4 Burnett HC, Nicholson DA. Current and future role of ultrasound in the emergency department. J Accid Emerg Med 1999;16:250-4.

5 Mandavia DP, Aragona J, Chan L, et al. Ultrasound training for emergency physicians - a prospective study. Acad Emerg Med 2000;7:1008-14.

6 Kuhn M, Bonnin RL, Davey MJ, et al. Emergency department ultrasound scanning for abdominal aortic aneurysm: accessible, accurate, and advantageous. Ann Emerg Med 2000;36:219-23.

7 Durston W, Carl ML, Guerra W. Patient satisfaction and diagnostic accuracy with ultrasound by emergency physicians. Am J Emerg Med 1999;17:642-6.

8 Lanoix R, Baker WE, Mele JM, et al. Evaluation of an instructional model for emergency ultrasonography. Acad Emerg Med 1998:5:58-63.

9 Ma OJ, Mateer JR, Ogata M, et al. Prospective analysis of a rapid trauma ultrasound examination performed by emergency physicians. J Trauma 1995;38:879-85.

\section{Call for papers}

11 th European Forum on Quality Improvement in Health Care 26-28 April 2006, Prague, Czech Republic Deadline 30 September 2005.

For further information and to submit online go to: www.quality.bmipg.com 